\title{
Entangled Reflections on Designing with Leaky Breastfeeding Bodies
}

\author{
Karey Helms \\ KTH Royal Institute of Technology \\ Stockholm, Sweden \\ karey@kth.se
}

\section{ABSTRACT}

Bodily transformations that attend breastfeeding include entanglements of more-than-human materials and agencies. These can be seen in exchanges of physical matter, such as bacteria, that blur bodily boundaries. I present three design explorations of my breastfeeding experiences as entangled: knitting bras for lopsided breasts, transforming milk into fiddling necklaces, and site-writing around breastfeeding. Through spatial and conceptual mappings of the explorations, I propose them as alternative narratives in designing for leaky breastfeeding bodies. I also offer two broader reflections on designing with, for, and among more-than-human bodily materials: generous absence and bodily mappings. The accompanying reading instructions to this bodily research open for further encounters and reflections between the three explorations.

\section{Authors Keywords}

Breastfeeding; leaky; more-than-human; posthumanism.

\section{CSS Concepts}

- Human-centered computing -Interaction Design

Permission to make digital or hard copies of part or all of this work for personal or classroom use is granted without fee provided that copies are not made or distributed for profit or commercial advantage and that copies bear this notice and the full citation on the first page. Copyrights for third-party components of this work must be honored. For all other uses, contact the Owner/Author

DIS '21, June 28-July 2, 2021, Virtual Event, USA (C) 2021 Copyright is held by the owner/author(s).

ACM ISBN $978-1-4503-8476-6 / 21 / 06$.

https://doi.org/10.1145/3461778.346204

\section{INTRODUCTION}

Milk is an interesting bodily fluid because it is secreted, not excreted, for another mammal to ingest. This verbal distinction is significant because unlike many bodily fluids, milk is not discharged as waste but is released for sustenance. Although for many humans, breastfeeding is more than just the secretion of milk from a mother to a child. It can also provide comfort and nurturing within the complex social and material relations of care-giving and care-receiving. Inherent to both perspectives is an intricate network of unknowable bodily exchanges and changes.

The transformations that attend maternity include morethan-human materials and interdependent agencies. For example, they involves bilateral exchanges of bacteria and relational processes of hormone stimulation [33]. This attention towards nonhumans is situated within critiques of anthropocentrism [1, 19, 21] that "greatly expands our understandings of the multiple agencies, dependencies, entanglements, and relations that make up our world" [19]. This perspective troubles understandings of breastfeeding as a unilateral transfer and milk as a commodity. In drawing upon Diprose's notion of corporeal generosity [17], Hird argues that inherent to breastfeeding is a gifting of physical matter, such as bacteria, with the potential for unanticipated outcomes as interdependent human and more-than-human bodies [27]. This gifting as "excess", as opposed to a closed economy of exchange, challenges cultural notions of what an independent breastfeeding "body" might be or include as an open leaking and mingling "between self and other, nurture and nature, human and nonhuman, foreign and familiar" [27]. In the context of interaction design, "leaky" bodily boundaries has been used to describe nonhuman systems and objects $[3,24,43]$, as well as to refer to how humans move [47] and "spill over" [50] within worlds. In designing with breastfeeding, leaky includes reckoning with more-than-human entanglements that disorders species boundaries and individual autonomy [45].

In the following, I present three ongoing design explorations from my breastfeeding experiences that are grounded within my own sense-making efforts as a mother and designer: knitting bras for lopsided breasts, transforming milk into fiddling necklaces, and site-writing around breastfeeding. Each design is grounded with felt frustrations and personal curiosities towards bodily undoings and becomings that continue to challenge and reframe my own cultura preconceptions and expectations of breastfeeding as a white, cis-gender, North American who resides in Northern Europe. My breastfeeding experiences began in summer 2019 and are ongoing during the writing of this pictorial.

In form, the explorations can be considered Design Memoirs [15] as embodied autobiographical designs that share emotional memories and invite reflexive narratives. They call upon a somatic first-person perspective [31] for intimate access to felt experiences in the designing and sharing within and beyond breastfeeding bodies. While none of the explorations explicitly involve technology, 
related research that helps further situate their relationship with interaction design includes: extending human bodies for noticing more-than-human entanglements [38], gut-tracking human microbiomes for reflection on morethan-human "selves" [10], magnifying saliva to share among humans the experience of fertility-tracking [28], and touching human body parts and fluids to produce new knowledge $[7,12,47]$.

While I undoubtedly consider breastfeeding an art [49], my intentions are not to advocate for or against it. Instead, my intentions in sharing these intimate designs are two-fold. The first attends to a politics of breastfeeding, and more specifically, breastfeeding as a relational and unpredictable exchange of matter $[11,27]$ and a valuing of reproductive labor and affect $[23,34,36,41]$. Within this, I propose alternative narratives of experience for designing within or for uncertainties [16], ambivalences [52], and perceived "choices" $[11,48]$ of parenting. Yet I also acknowledge that my lived experiences are particular among a plurality.

The second attends to a politics of design, whereby I offer two broader reflections for designing with, for, and among more-than-human materials: generous absence and bodily mappings. Generous absence reframes absence as "nonexistence" or a "lack of" to an inclusion of presence in unfamiliar forms and an openness towards the potential material consequences of design interventions. Bodily mappings methodologically approaches bodies as entangled through a focus on layers of relations for subject diversities and layers of activity for ongoing becomings. The two reflections, like my experiences as a breastfeeding mother and designer, are by no means separate, distinct, or complete. The following presentation of them reflects their entanglement within my intentions and among the designs.

\section{Bodily Instructions}

In taking advantage of the pictorial format [42], I suggest readers to bodily engage with this research by: 1) physically printing or digitally exporting all pages individually; and 2) arranging pages according to the mapping to the right. Page numbers correspond to the document's stand alone ordering, rather than the proceeding's numbering.
These instructions represent my methodology, whereby I first placed the site-writings on pages 4-12 according to their order in the poem on page 3; and then arranged pages 4-12 according to their approximate spatial locations as physical places. I then went through multiple iterations of moving the pages according to emergent themes as I added annotations and photos of the other two design explorations. In doing so, some spatial locations remain physically accurate (e.g. the bathtub is next to the bedroom), and others are shifted in accordance to conceptual relationships between explorations.

These instructions also intentionally invite other bodily mappings, or mappings refusals, that open for unanticipated encounters and research findings beyond my own two initial reflections. Thus, the mapping below is one possible approach that if followed, I recommend beginning with page 3 and reading from top to bottom, and from left to right. A highresolution pre-arranged version of this mapping is available as a supplemental file in the ACM Digital Library and at www.kareyhelms.com/pdf/leaky-breastfeeding-bodies.pdf.
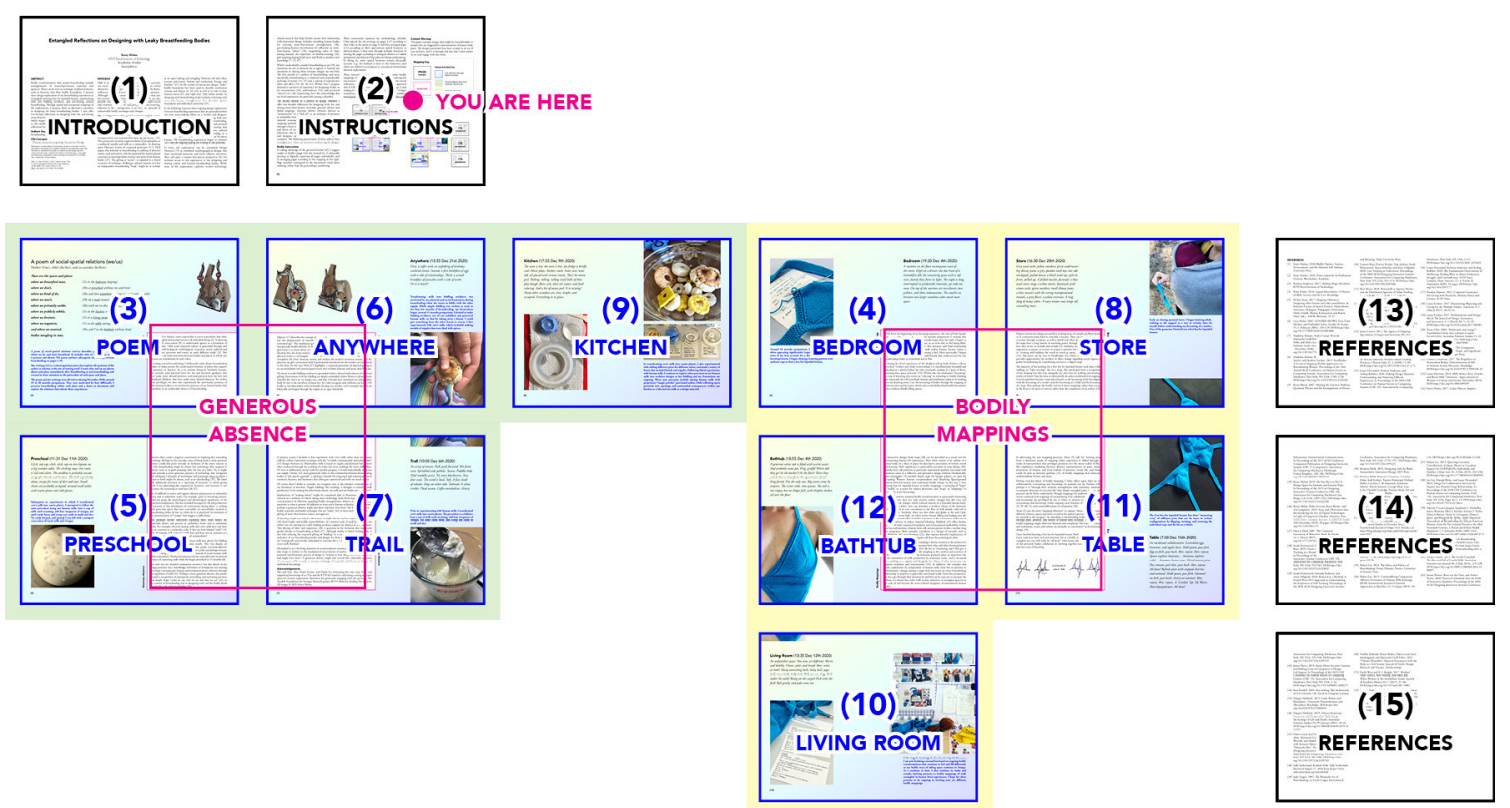

\section{Content Warning}

This paper contains images that might be uncomfortable to people who are triggered by representations of human body parts. The designs presented have been created as an act of care and love, and it is through this lens that I wish readers to see and engage with this work.

\section{Mapping Key}

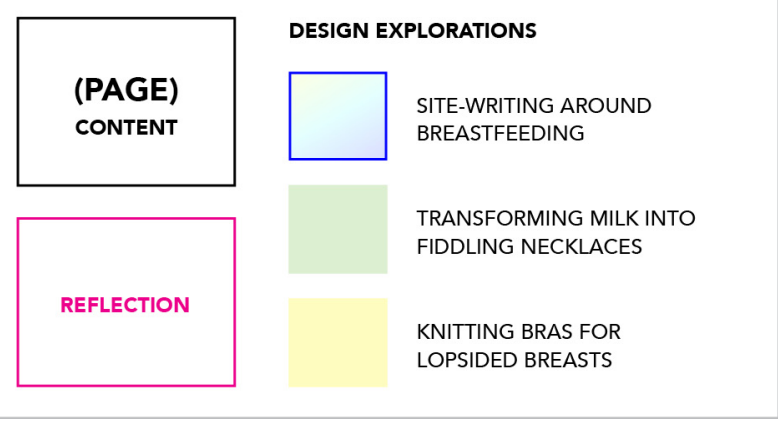




\section{A poem of social-spatial relations (we/us)}

Mother (I/me), child (she/her), and co-caretaker (he/him)

These are the spaces and places

where we breastfeed most,

(Us in the bedroom sleeping)

where we don't,

(She at preschool without me and him)

where we kind of do,

(She and him anywhere without me and with a bottle)

where we won't,

(Me on a trail running without her and him)

where we privately suckle,

(She with me in sling at the store)

where we publicly nibble,

(Us in the kitchen visible to neighbors)

where we hesitate,

(Us in a living room with others)

where we negotiate,

(Us at the table eating)

and where we unwind,

(She and I in the bathtub without him)

bodies mingling in time.

A poem of social-spatial relations (we/us) describes physical locations where we do and don't breastfeed. It includes who of us, and not of $u s$, is present and absent. The poem outlines subsequent site-writings around breastfeeding on pages 4-10.

Site-writing [44] is a critical spatial practice that explores the position of the author in relation to the site of writing itself. I wrote after and on my phone about each place immediately after breastfeeding or not breastfeeding; and around to draw attention to the particulars of each space and place.

The poem and site-writings were all written during December 2020, around 19 to 20 months postpartum. They were motivated by how differently I perceive breastfeeding within each place and a desire to document and explore the relations that inform these experiences.

As put forth by Alaimo, trans-corporeality is a new materialism that refers to the entangled relationship between all embodied beings [2]. In drawing upon Barad's intra-action [9], it understands agency as a dynamism of forces whereby "[t]he trans-corporeal subject is generated through and entangled with biological, technological, economic, social, political and other systems, processes and events, at vastly different scales" [2]. This foregrounds an interconnection between bodies and places in which one another are transformed by each other.

In writing around breastfeeding, I deliberately make absent breastfeeding bodies, to make present the social-spatial relations of places that support its presence or absence. As a cis woman living in Northern Europe, this includes paid parental leave for me and lactation guidance that have made easier desired presence, and paid parental leave for him and subsidized childcare that have made easier desired absences. Yet within these privileges, we have also experienced the unwelcome presence of other human bodies or an unwelcome presence of our human bodies that contribute to an undesirable absence of breastfeeding. 


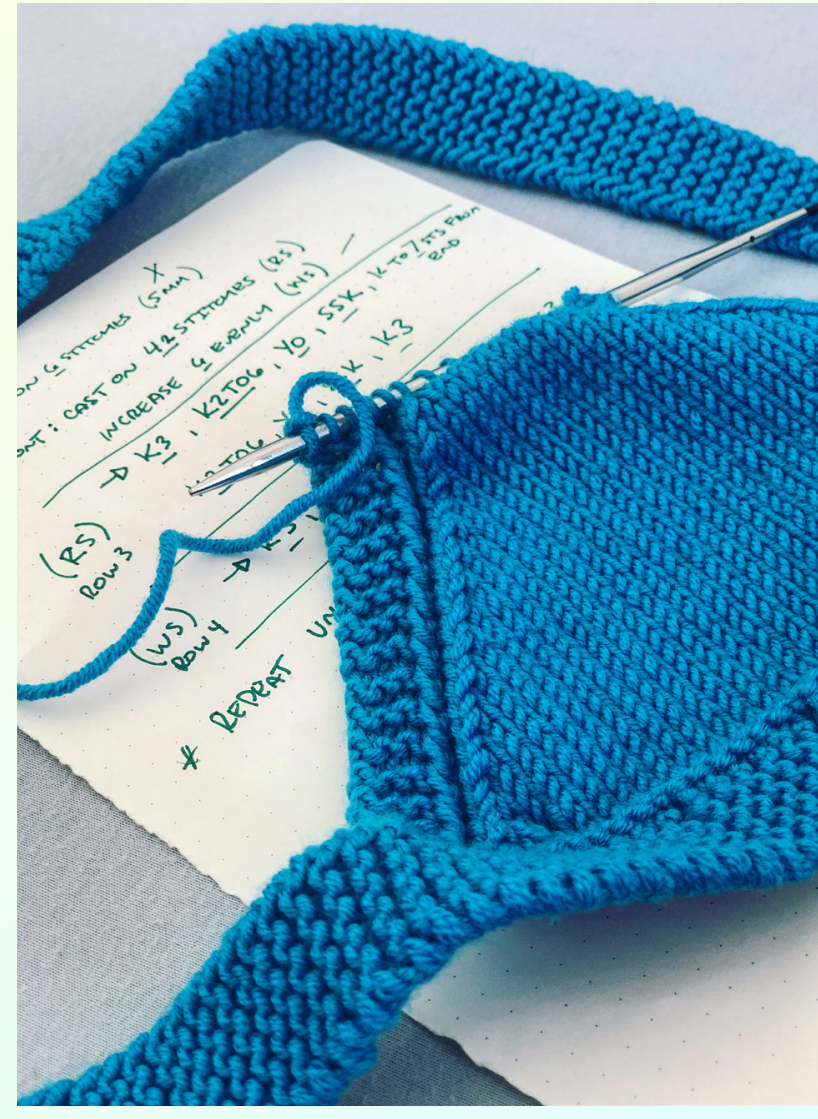

Around 10 months postpartum, I noticed one breast often appearing significantly larger than the other. As none of my bras account for a dynamic asymmetry of lactating breasts, I began altering a knitting pattern with uniform cups to knit a bra for lopsided breasts.

\section{Bedroom (19:20 Dec 4th 2020)}

A mattress on the floor encompasses most of the room. High on a dresser, the low hum of a humidifier fills the remaining space with a soft mist, faintly blue from its light. The night is long, interrupted in predictable intervals, yet ends too soon. On top of the mattress are two duvets, two pillows, and three indentations. The smaller in between two larger somehow takes much more space.

While from the beginning of my lactating experience, the sizes of both breast were constantly shifting, at around 10 months postpartum I noticed that within their dynamism, the left was generally larger than the right. I began to reflect upon what it means for them, me, or us to be full, to feel being filled, and to fill up space unevenly together. This dynamic and fluid relationship between bodies and spaces includes milk within breasts, breasts within a bra, a bra among bodies, and bodies among a bed. More practically, I began adapting a pattern to knit bras for lopsided breasts that could account for our breastfeeding bodies as networked and in flux.

In sharing her lived experiences of the disabled cyborg body, Forlano reflects upon how "[w] hen one's body is networked, it is simultaneously bounded and embodied in a physical place but also constantly existing in a space of flows, traversing time, space and scale" [18]. Within this, she emphasizes "becoming" as a way of knowing that resists an "othering" in attending to bodily thinking that transcends the self as multiple human and nonhuman subjects. In looking upon my knitting notes, I see the becoming of bodies through the mapping of stitch increases and decreases, which aims to destabilize fixed bodily boundaries and to embrace fluidly filling spaces. 


\section{Preschool (11:31 Dec 11th 2020)}

Click, tap tap, click, click, tap on two laptops on a big wooden table. The clicking stops, this room is still and silent. The sandbox is probably vacant, except for shovels and buckets. The ball is probably alone, except for traces of dirt and snot. Small chairs are probably occupied, around small tables with warm plates and cold glasses.

Subsequent to experiments in which I transformed cow's milk into casein plastic, I attempted to follow the same procedure using our human milk: heat a cup of milk until steaming, add four teaspoons of vinegar, stir until curds form, and scoop out curds to mold and dry. No curds formed, and instead I was left with a pungent concoction of warm milk and vinegar.

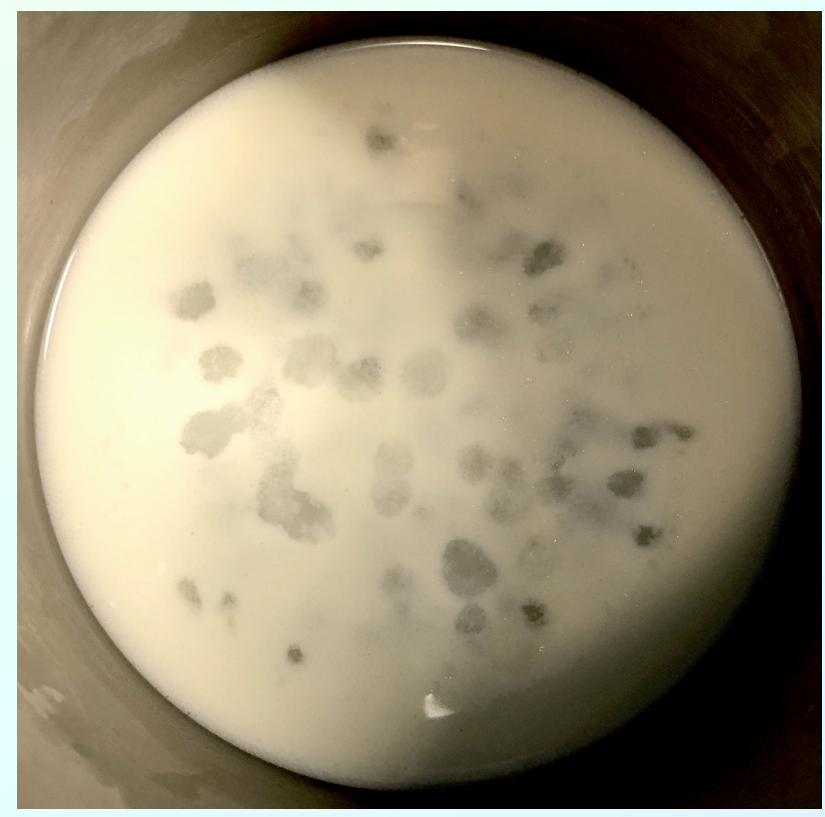

Absence often carries a negative connotation in implying that something is missing. Perhaps in the everyday sense of being kind, a more generous absence could also point towards an inclusion of the many reasons as to why breastfeeding might be absent but technology that supports it present, such as in grief pumping after the loss of a baby. Or, it might point towards a more generous presence of technology that recognizes and celebrates a diversity of nourishing and nurturing practices when a breast or birth might be absent, such as in chestfeeding [35]. The latter calls additional attention to a "queering of lactation" in which giving birth is not physiologically required for lactation, and lactation is not necessary for nurturing or nutrition [20,37].

Yet, it's difficult to notice and support absence and presence in unfamiliar forms and at unfamiliar scales. For example, prior to becoming parents, I did not grasp the psychological and physiological significance of his material entanglement. This has included massages for the felt production of oxytocin in the stimulation of contractions during labor; a cooking with particular spices that have noticeably, yet unverifiably, resulted in breastfeeding strikes by her; or, while she is at preschool, his imitation of her pronunciation of "orange" that triggers a milk release.

This prompts further reflections regarding what other bodies are materially absent and present in unfamiliar forms and at unfamiliar scales. For example, what do human milk and cow's milk have and have not in common at a molecular scale, if they are both labeled "milk"? Or, what do human milk and cow's milk have and have not in common at a lawful scale, if they are both considered commodities?

In my failed attempt to transform human milk into plastic for fiddling necklaces, I naively expected the same results. This was despite an awareness of compositional differences that guide recommendations regarding when a human baby can drink cow's milk, and perhaps because of her drinking glasses of cold cow's milk instead of warm human milk while at preschool. This known presence for her coincided with my desired absence of expressing milk when she began preschool at 15 months old.

Not only was my material assumption incorrect, but also absent in my design processes was a knowledge of histories of interspecies wet nursing that shape contemporary human and nonhuman power relations through the regulation of milk [41]. Perhaps a more generous absence also points towards a recognition of interspecies nourishing and nurturing practices that deeply shape "what we eat, who we eat and how we eat" [41] in the context of breastfeeding and in designing with and for bodily fluids beyond the scale of human bodies [25]. 

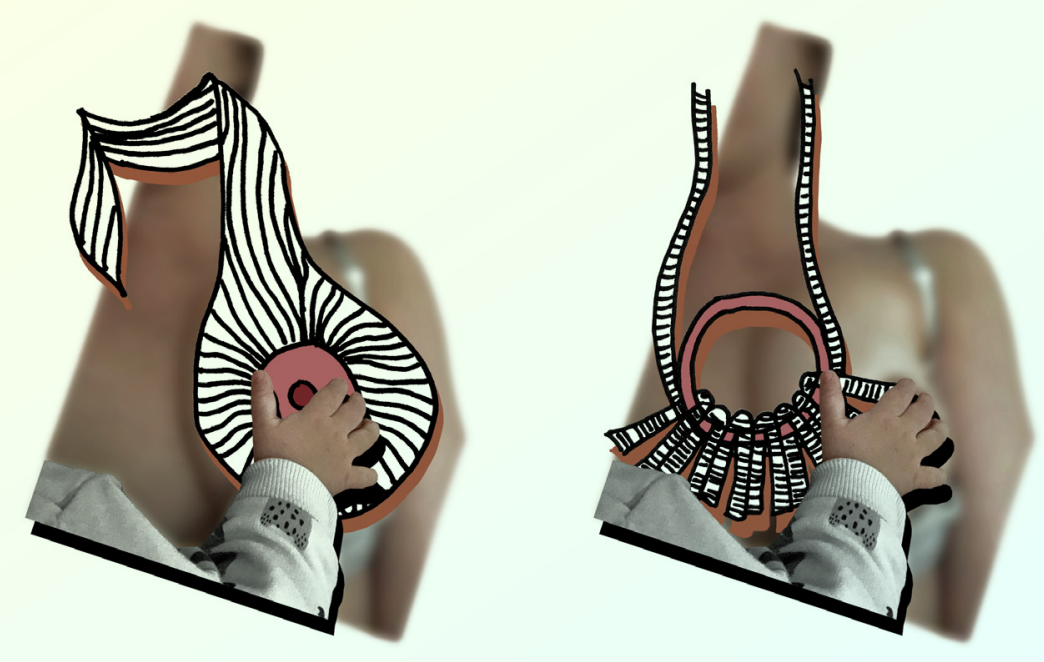

Diprose [17] describes the concept of generosity as "not the expenditure of one's possession but the dispossession of oneself, the being-given to others that undercuts any selfcontained ego". She emphasizes generosity as an openness to others and to transformation that precedes bodily identity. In the context of maternity, Hird [27] suggests that corporeal generosity is as much about an openness to possibilities as a threat to bodily integrity. To illustrate this, she draws attention to the "very real material processes of maternity" whereby physical matter is exchanged, or gifted. For example, the placenta can gift chemicals that strengthen the fetus' immune system and weaken the mother's immune system, and the placenta can gift a premature birth if periodontal microbes from the mother are transferred to the fetus. In this way, Hird [27] highlights a corporeal generosity of material gifting as an uncontrollable and unanticipated excess that includes humans and more-than-humans.

My desire to make fiddling necklaces is grounded within cultural ambivalences of maternal gifting. Frustrations with her fiddling are deeply embedded within Western cultural biases whereby she and I are no longer one, and that I should have reclaimed my independent body by now to be anywhere without her. Yet I also recognize and celebrate our leaky [45] bodies as interdependent and continually altering one another, as for example, bacteria are bilaterally exchanged through the nipple as an open threshold.
Anywhere (13:55 Dec 21st 2020)

First, a coffee with an unfolding of birthday weekend stories. Second, a first breakfast of eggs with a side of relationships. Third, a second breakfast of pancakes with a side of work. Or is it lunch?

Transforming milk into fiddling necklaces was motivated by my physical and social frustrations during breastfeeding when she wants to fiddle with the other nipple. While nipple fiddling was evident as early as the first few months of breastfeeding, my frustrations began around 11 months postpartum. I desired to make fiddling necklaces out of our solidified and preserved human milk, so that by taking away a breast, I could give something from the other breast in return. I first experimented with cow's milk, which included making models of nipples that were dyed with spices.

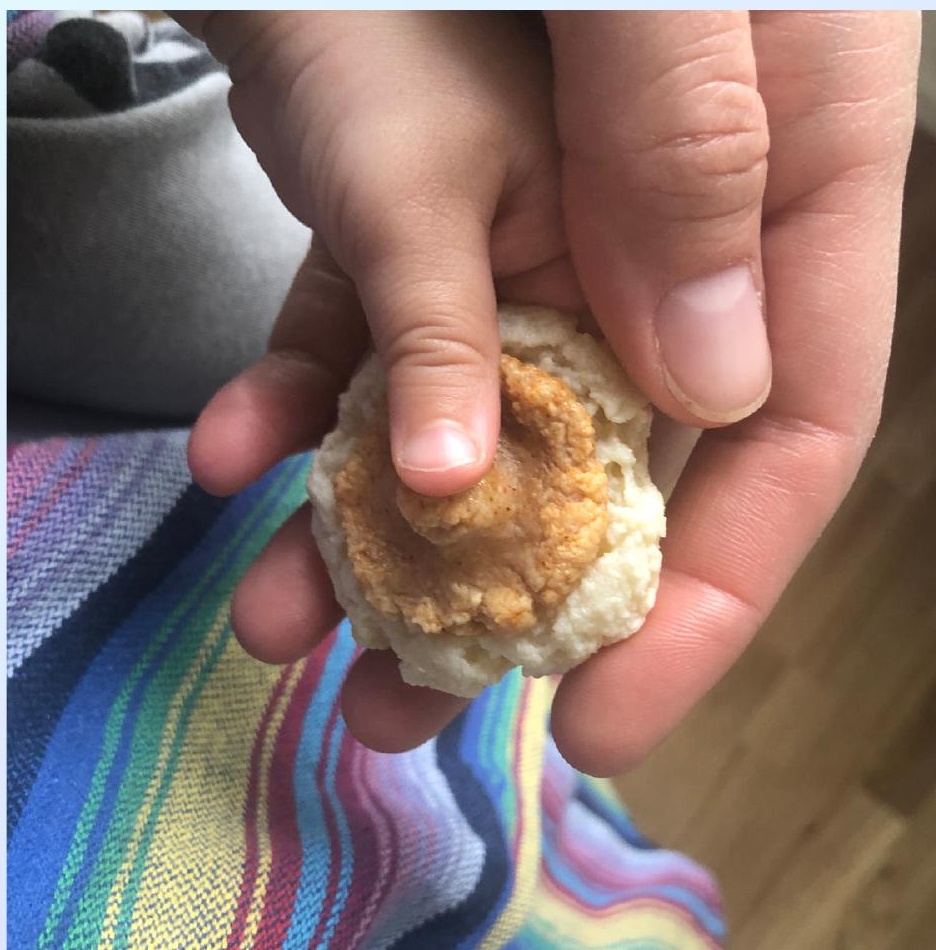


A primary reason I decided to first experiment with cow's milk rather than our human milk lay within a hesitation to tamper with the "invisible, immeasurable and unknowable" [41] hunger between us. Mammalian milk is based on supply and demand that is most often evidenced through the suckling of a baby: the more suckling, the more milk. Thus, if I were to deliberately extract milk for another purpose, it would undoubtedly influence our supply. Otomo [41] more generously refers to this relationship between breastfeeding bodies as "the gentle cannibal": a reference towards the emotional and material gifting of nutrients, bacteria, and hormones that often goes unnoticed and with too much notice.

Of course what I failed to consider, yet recognize now, is the inherent contradiction of my hesitation to interfere. Nipple fiddling, like suckling, is thought to stimulate milk production. So by making the other breast absent, our milk and our bodies are transformed.

Implications of "making absent" might be considered akin to Homewood et al.'s [29] removal as a method, in which taking away technology from lived experience can be a critical practice of reflection regarding bodily entanglements: absence as a strategy to pay attention to what is present. In addition to intra-active human-technology entanglements, perhaps a generous absence might also draw attention away from "the body" and towards bodily materials and bodily exchanges that are "leaky" [45] in their inclusion of corporeal gifting of more-than-human matter and agencies.

Technology might not only be taken away, it might also be used to support "being away" [26] from bodies and bodily responsibilities. At a human scale, if used by him with her while I am out running on a trail, fiddling necklaces support my absence as a replacement. This sharing of labor and experience [28] is generous in his inclusion that transcends gender divides in breastfeeding as fluid [37]. Although similar to bottle feeding [34], it also risks reducing the corporeal gifting of "fiddling" to a commodity. These conflicts are indicative of our breastfeeding bodies and designs for them as "living artefacts" [32] that are "ecologically and socially embedded in everyday life [...] in a biodesign process that is never really finished".

Devendorf et al. [16] bring attention to social-technical constructs of good parenting that take shape in relation to the fundamental uncertainties of mothering. They highlight the potential transformative process of design to "remind us how things are, were, might be, and might have been". A generous absence might also extend this vulnerable openness of intra-action [9] towards a constant exchange of materials and forces in futures of unfinished becomings.

\section{Acknowledgements}

Her and him. Mai, Marie Louise, and Nadia for welcoming her into your lives, and supporting becomings of us. Ylva and the KTH IxD team for cultivating a caring and open space for creative exploration. Reviewers for generously engaging with this pictorial. The Swedish Foundation for Strategic Research project RIT15-0046 for funding this research. All images (c) 2021 Karey Helms.

\section{Trail (10:05 Dec 6th 2020)}

An array of moons. Pulls path forward. Wet from rain. Sprinkled with pebbles. Swans. Puddles hide. Mud muddles paces. No more blueberries. Two deer wait. The wind is loud. Soft. A fast cloud of exhales. Dogs on either side. Tethered. A silent stroller. Plaid season. Coffee metabolizes. Heavy.

Prior to experimenting with human milk, I transformed cow's milk into casein plastic. The procedure is as follows: heat a cup of milk until steaming, add four teaspoons of vinegar, stir until curds form, and scoop out curds to mold and dry.

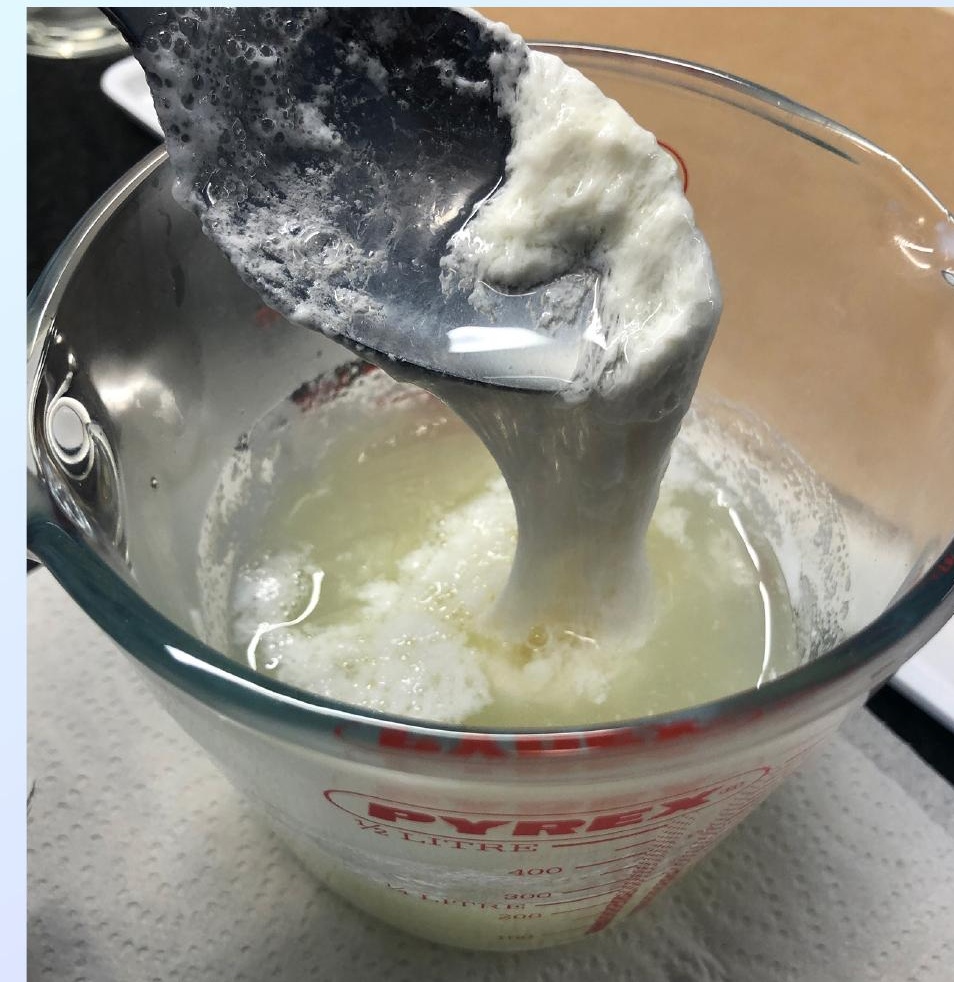




\section{Store (16:30 Dec 20th 2020)}

Grey wool socks; yellow sneakers; green underwear; big skinny jeans; a grey spandex tank top, one side unclipped, pulled down; a black wool top, split in front, pulled up. A folded muslin, fastened; a blue wool cover, snug; a white onesie, buttoned; pink cotton socks; green sneakers; small skinny jeans; a blue sweater with the wrong monogrammed initials; a grey fleece; a yellow overcoat. A ring sling of many colors. A navy winter coat wraps all, concealing most.

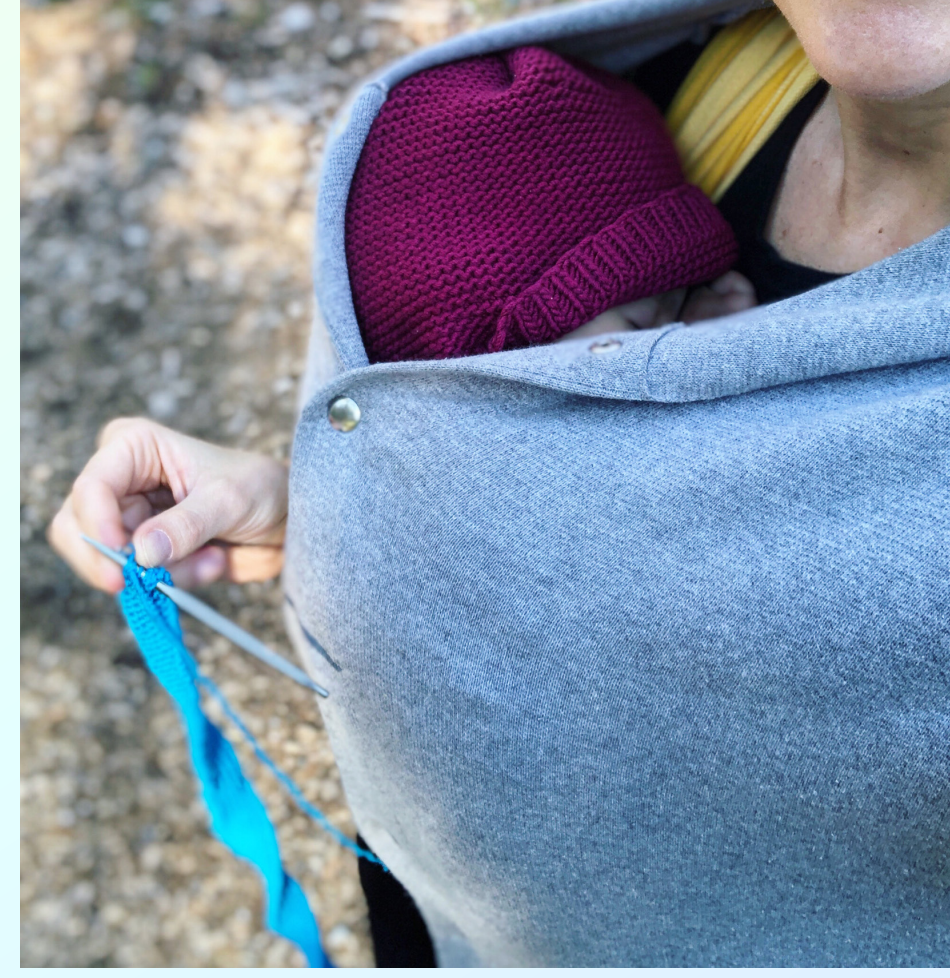

Early on during parental leave, I began knitting-whilewalking as she napped as a way to reclaim time for myself within understanding my becoming of a mother. One of the garments I knitted was a first bra for lopsided breasts.
Maps in interaction design are useful in making sense of complex problem spaces or in communicating hard to articulate concepts. They can provide clarity and structure through synthesis, as well as distill and refine through representation. Yet maps have a long history of narrating power through what they choose, or how they invite, to include and exclude [5]. Similarly, maps can also be used in opposition to power, or as ways to reopen a narrative for revision and remaking in "creating and building the world as much as measuring and describing it" [13]. The latter can be seen in FeedFinder [8], which is an application that provides opportunities for mothers to affect change regarding social stigmas of public breastfeeding by contributing reviews to a digital map.

The majority of the knitting for a first bra for lopsided breasts took place while walking, or "baby-wearing", her in a wrap. This developed from a recognition of her sleeping best this way, alongside my own love for walking and knitting, neither of which I had the time to substantially do unless combined with napping. A stitch somehow became a step and a breath, as the becoming of the bra aligned with the becoming of a mother and the becoming of a child and the becoming of a map. Thus perhaps this bodily activity is about mappings rather than a map, as the focus is on layers of activity rather than the completion of an artifact [13]. 


\section{Living Room (13:35 Dec 12th 2020)}

An unfamiliar space. Not new, yet different. Warm and bubbly. Cheese, patté, and bread. Beer, wine, or both? Many interesting balls: holey ball, yoga ball, meat balls, belly ball. Roll, sit, eat, hug. Kick under the table! Boing on the carpet! Pick with the fork! Rub gently, and poke some too.

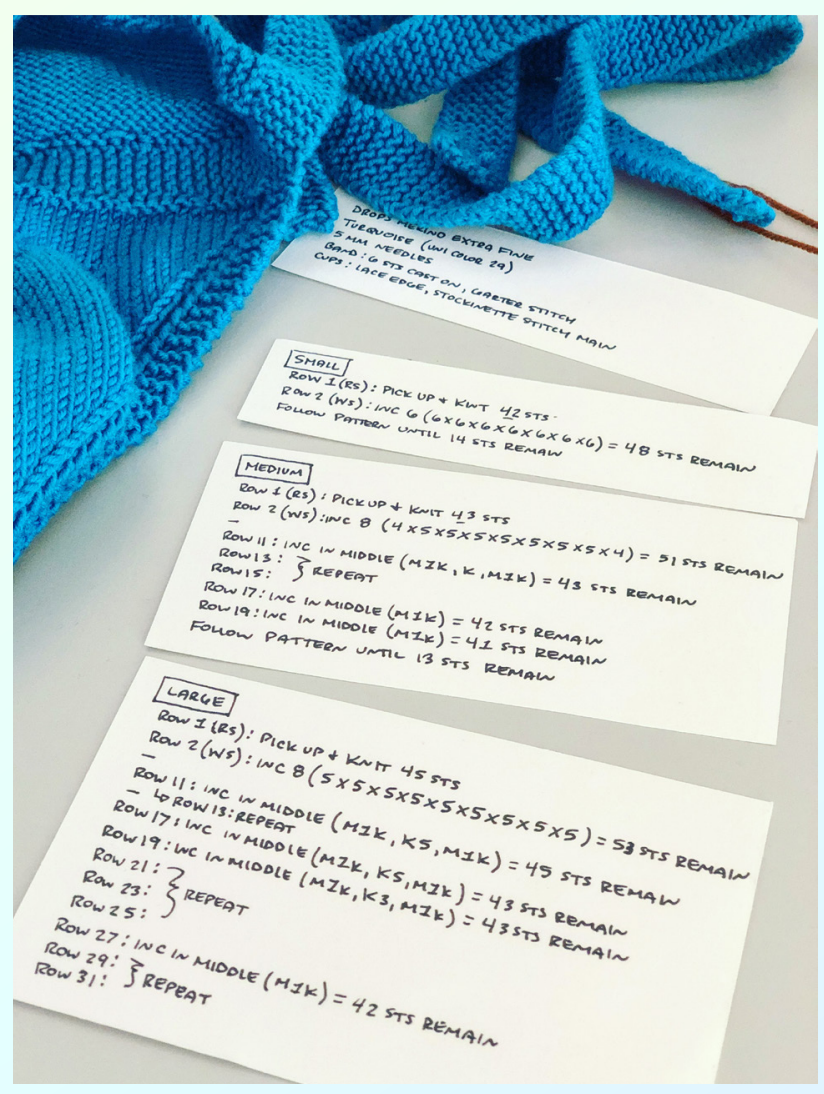

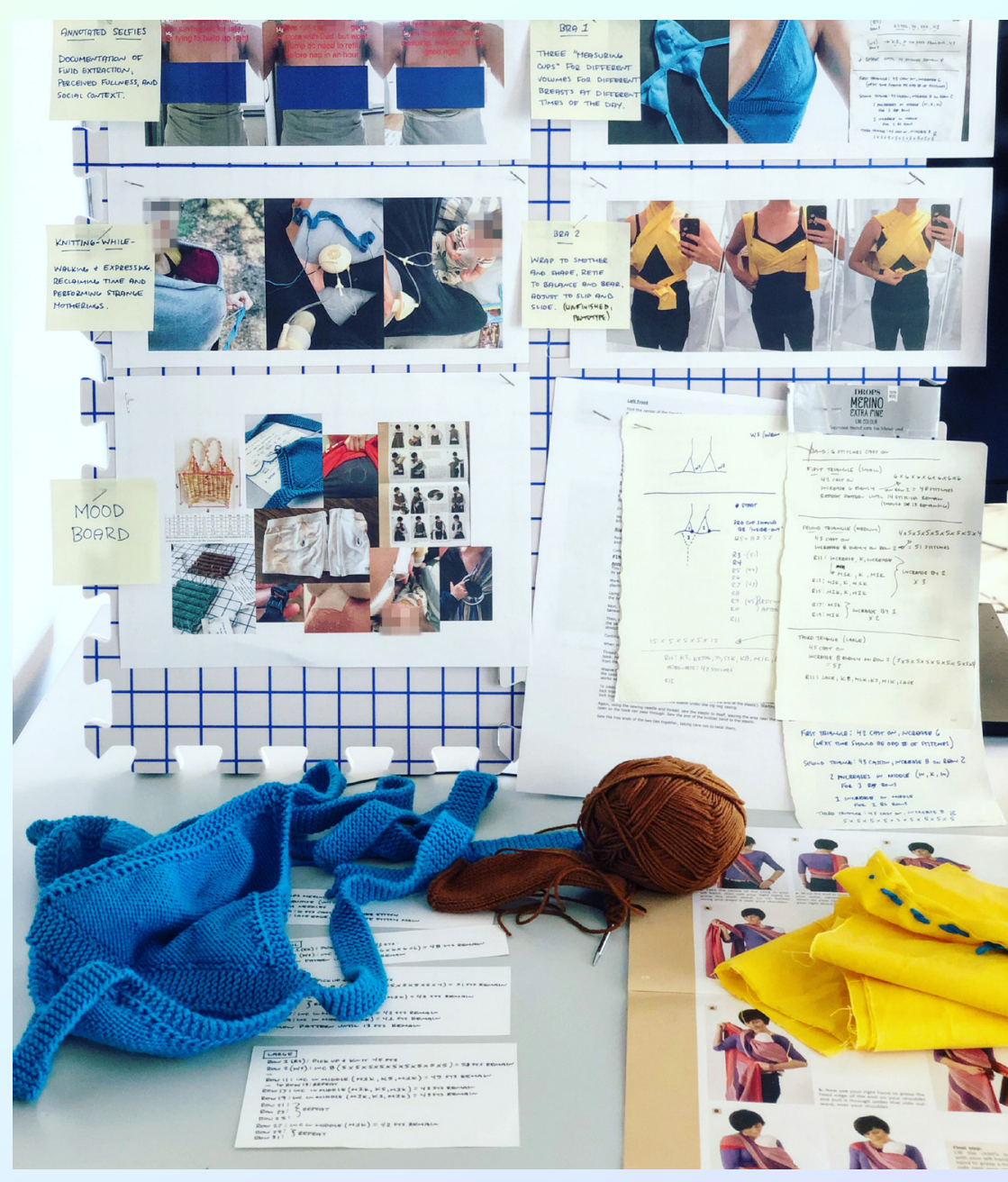

Following the knitting of a first bra for lopsided breasts, I am now knitting a second bra based on ongoing bodily transformations that continue to feel and fill differently as our bodily ways of taking space continue to change. As I continue to knit, I also continue to make and remake knitting patterns as bodily mappings of milk entangled in human lived experiences. I hope for these patterns to be ongoing in inviting new, yet different bodily mappings. 


\section{Bathtub (18:55 Dec 4th 2020)}

A generous white tub is filled with warm water. And probably some pee. Frog, giraffe! Where did they go? In the bucket? On the floor? There they are! Is that a noise from the apartment above?

Frog farted. Not the only one. Big waves come by surprise. The water stills, time pauses. The tub is not empty, but no longer full, with droplets shaken all over the floor.

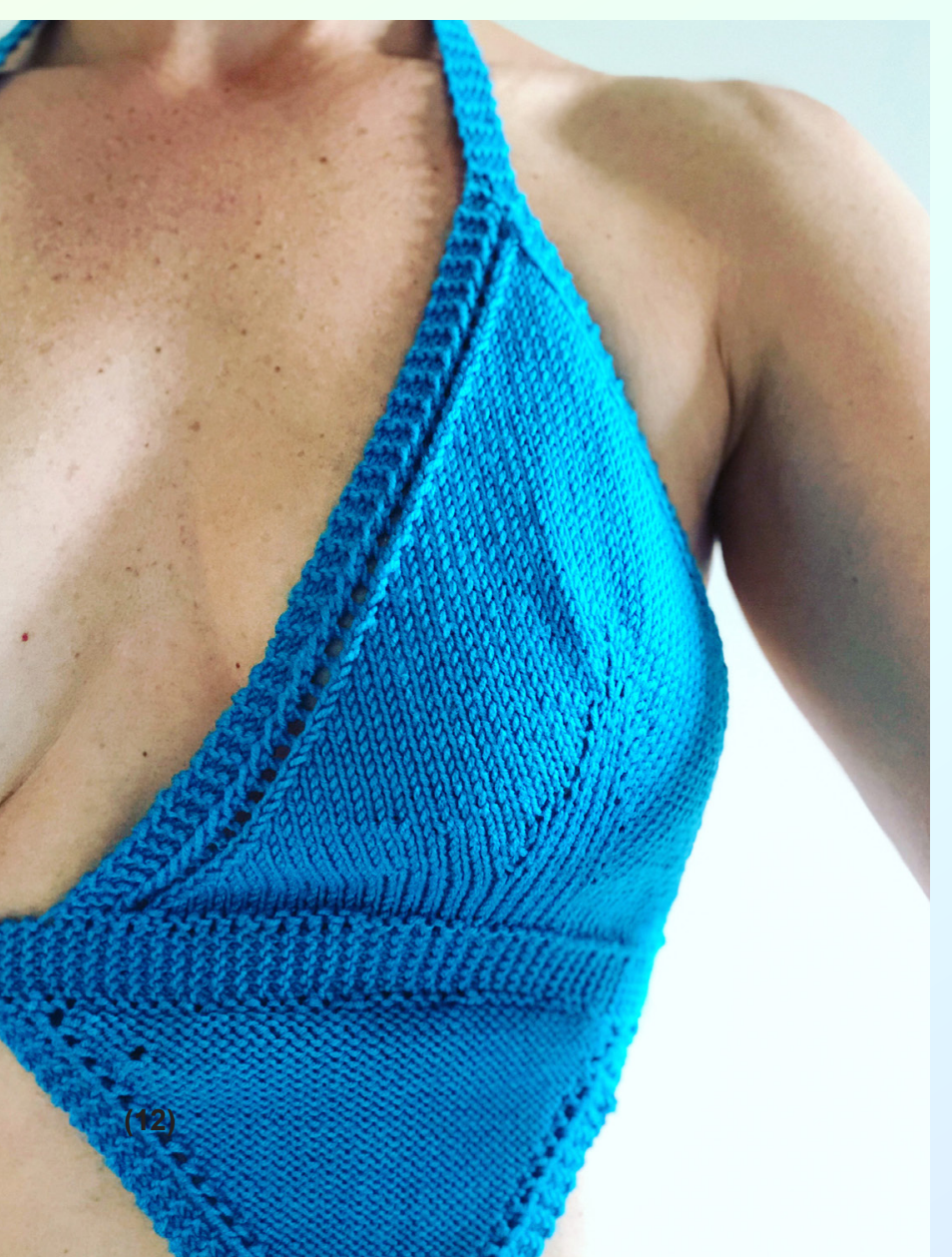

In interaction design, body maps [30] can be described as a visual tool for documenting human felt experiences. They often consist of an outline of a human body on a sheet of paper for descriptive annotation of written words and drawing. Their significance is particularly prevalent in soma design [30], whereby they call attention to particular experiential qualities associated with a human's soma as a reflective and generative design method. Paradoxically, trans-corporeality [2] similarly begins with the human subject, yet aims for disrupting Western human exceptionalism and dissolving figure/ground relations between human and nonhuman bodily beings. In this way, I view knitting bras for lopsided breasts as bodily mappings: a reframing of "body" as "bodily" to account for subject diversities, and "maps" as "mappings" to account for active becomings.

Bailey [6] positions maternal bodily transformations as particularly interesting because of how they not only involve surface changes but also very real internal material changes within cultural notions of a bounded human body. For example, a baby's cries can stimulate a mother's release of the hormone oxytocin, which in turn contributes to the flow of milk already collected in the breast [33]. Similarly, when our skin slides and glides as she and I play together in a warm bath, we often notice breasts filling and leaking into the tub. This hormonal reflex is further important in the contraction of the uterus following delivery to reduce maternal bleeding. Shildrick [45] offers further examples of leaky corporeal boundaries and intracorporeal malleability within fetal microchimerism, whereby fetal cells remain present within a mother long after pregnancy. Both examples contribute to a lineage of research, such as by Shildrick [46] and Haraway [22], that exposes harmful implications of maintaining and protecting a singular self from the pathological other.

While a bra in its everyday understanding is clearly oriented to the surface of a bounded human body, in reflecting upon how, why, and when lactating breasts physically take space, I began to view the bra as "measuring cups" that give a material surface to a complex bodily mingling in the creation and secretion of milk. In addition to oxytocin, the hormone prolactin plays an important role in the stimulation of milk production by mammary tissue, and is increased by a suckling on a nipple; and alongside the release of other hormones, can suppress ovulation and menstruation [33]. In addition, the complex and barely understood [4] composition of human milk, from fats to proteins to carbohydrates, changes during a single feed and across an entire breastfeeding relationship in response to particular nutritional needs. From this perspective, the bra cups through their dynamic fit and feel can be seen not to measure the fullness of a breast, but rather milk as data indicative of entangled agencies at the scale of and beyond the socio-cultural imaginary of autonomous human bodies. 


\section{REFERENCES}

[1] Stacy Alaimo. 2010. Bodily Natures: Science, Environment, and the Material Self. Indiana University Press.

[2] Stacy Alaimo. 2018. Trans-corporeal. In Posthuman Glossary. Bloomsbury Academic.

[3] Kristina Andersen. 2017. Making Magic Machines. KTH Royal Institute of Technology.

[4] Peter Atkins. 2016. Liquid Materialities: A History of Milk, Science and the Law. Routledge.

[5] Nishat Awan. 2017. Mapping Otherwise: Imagining other futures and other possibilities. In Feminist Futures of Spatial Practice: Materialisms, Activisms, Dialogues, Pedagogies, Projections, Meike Schalk, Thérèse Kristiansson and Ramia Mazé (eds.). AADR, Baunach, 19-27.

[6] Lucy Bailey. 2001. GENDER SHOWS: First-Time Mothers and Embodied Selves. Gender \& Society 15, 1 (February 2001), 110-129. DOI:https://doi. org/10.1177/089124301015001006

[7] Madeline Balaam, Nadia Campo Woytuk, Marianela Ciolfi Felice, Ozgun Kilic Afsar, Anna Ståhl, and Marie Louise Juul Søndergaard. 2020. Intimate touch. interactions 27, 6 (November - December 2020), 14-17. DOI:https://doi. org/10.1145/3427781

[8] Madeline Balaam, Rob Comber, Ed Jenkins, Selina Sutton, and Andrew Garbett. 2015. FeedFinder: A Location-Mapping Mobile Application for Breastfeeding Women. Proceedings of the 33rd Annual ACM Conference on Human Factors in Computing Systems. Association for Computing Machinery, New York, NY, USA, 1709-1718. DOI:https://doi.org/10.1145/2702123.2702328

[9] Karen Barad. 2007. Meeting the Universe Halfway: Quantum Physics and the Entanglement of Matter and Meaning. Duke University Press.

[10] Laurens Boer, Harvey Bewley, Tom Jenkins, Sarah Homewood, Teresa Almeida, and Anna Vallgårda. 2020. Gut-Tracking as Cultivation. Proceedings of the 2020 ACM Designing Interactive Systems Conference. Association for Computing Machinery, New York, NY, USA, 561-574. DOI:https://doi. org/10.1145/3357236.3395588

[11] Kate Boyer. 2018. Breastmilk as Agentic Matter and the Distributed Agencies of Infant Feeding. Studies in the Maternal 10, 1 (August 2018). DOI:https://doi.org/10.16995/sim.257

[12] Nadia Campo Woytuk, Marie Louise Juul Søndergaard, Marianela Ciolfi Felice, and Madeline Balaam. 2020. Touching and Being in Touch with the Menstruating Body. In Proceedings of the 2020 CHI Conference on Human Factors in Computing Systems (CHI '20). Association for Computing Machinery, New York, NY, USA, 1-14 DOI:https://doi.org/10.1145/3313831.3376471

[13] James Corner. 2011. The Agency of Mapping: Speculation, Critique and Invention. 89-101. DOI:https://doi.org/10.1002/9780470979587. $\operatorname{ch} 12$

[14] Stephanie DeVane-Johnson, Cheryl Woods Giscombe, Ronald Williams, Cathie Fogel, and Suzanne Thoyre. 2018. A Qualitative Study of Social, Cultural, and Historical Influences on African American Women's Infant-Feeding Practices. J Perinat Educ 27, 2 (2018), 71-85. DOI:https://doi.org/10.1891/1058-1243.27.2.71

[15] Laura Devendorf, Kristina Andersen, and Aisling Kelliher. 2020. Making Design Memoirs: Understanding and Honoring Difficult Experiences. In Proceedings of the $2020 \mathrm{CHI}$ Conference on Human Factors in Computing Systems (CHI '20). Association for Computing
Machinery, New York, NY, USA, 1-12. DOI:https://doi.org/10.1145/3313831.3376345

[16] Laura Devendorf, Kristina Andersen, and Aisling Kelliher. 2020. The Fundamental Uncertainties of Mothering: Finding Ways to Honor Endurance, Struggle, and Contradiction. ACM Trans. Comput.-Hum. Interact. 27, 4, Article 26 (September 2020), 24 pages. DOI:https://doi. org/10.1145/3397177

[17] Rosalyn Diprose. 2012. Corporeal Generosity: On Giving with Nietzsche, Merleau-Ponty, and Levinas. SUNY Press.

[18] Laura Forlano. 2017. Maintaining, Repairing and Caring for the Multiple Subject. continent. 6, 1 (March 2017), 30-35-35.

[19] Laura Forlano. 2017. Posthumanism and Design. She Ji: The Journal of Design, Economics, and Innovation 3, 1 (March 2017), 16-29. DOI:https://doi.org/10.1016/j.sheji.2017.08.001

[20] Fiona Giles. 2004. "Relational, and strange": A preliminary foray into a project to queer breastfeeding. Australian Feminist Studies 19, 45 (November 2004), 301-314. DOI:https://doi. org/10.1080/0816464042000278981

[21] Donna J. Haraway. 2007. The Companion Species Manifesto: Dogs, People, and Significant Otherness. Prickly Paradigm Press.

[22] Donna J. Haraway. 2017. The Biopolitics of Postmodern Bodies: Determinations of Self in Immune System Discourse. Routledge. DOI:https://doi.org/10.4324/9781315094106-24

[23] Laura Harrison. 2018. Milk Money: Race, Gender and Breast Milk "Donation." Signs: Journal of Women in Culture and Society (November 2018). DOI:https://doi.org/10.1086/699339

[24] Karey Helms. 2017. Leaky Objects: Implicit 
Information, Unintentional Communication. In Proceedings of the 2017 ACM Conference Companion Publication on Designing Interactive Systems (DIS '17 Companion), Association for Computing Machinery, Edinburgh, United Kingdom, 182-186. DOI:https://doi. org/10.1145/3064857.3079142

[25] Karey Helms. 2019. Do You Have to Pee? A Design Space for Intimate and Somatic Data. In Proceedings of the 2019 on Designing Interactive Systems Conference (DIS '19), Association for Computing Machinery, San Diego, CA, USA, 1209-1222. DOI:https://doi. org/10.1145/3322276.3322290

[26] Karey Helms, Pedro Ferreira, Barry Brown, and Airi Lampinen. 2019. Away and (Dis)connection: Reconsidering the Use of Digital Technologies in Light of Long-term Outdoor Activities. Proc. ACM Hum.-Comput. Interact. 3, GROUP, Article 230 (December 2019), 20 pages. DOI:https://doi. org/10.1145/3361111

[27] Myra J. Hird. 2007. The Corporeal Generosity of Maternity. Body \& Society 13, 1 (March 2007), 1-20. DOI:https://doi. org/10.1177/1357034X07074760

[28] Sarah Homewood, Harvey Bewley, and Laurens Boer. 2019. Ovum: Designing for Fertility Tracking as a Shared and Domestic Experience. In Proceedings of the 2019 on Designing Interactive Systems Conference (DIS '19). Association for Computing Machinery, New York, NY, USA, 553-565. DOI:https://doi. org/10.1145/3322276.3323692

[29] Sarah Homewood, Amanda Karlsson, and Anna Vallgårda. 2020. Removal as a Method: A Fourth Wave HCI Approach to Understanding the Experience of Self-Tracking. Proceedings of the 2020 ACM Designing Interactive Systems
Conference. Association for Computing Machinery, New York, NY, USA, 1779-1791. DOI:https://doi. org/10.1145/3357236.3395425

[30] Kristina Höök. 2018. Designing with the Body: Somaesthetic Interaction Design. MIT Press.

[31] Kristina Höök, Baptiste Caramiaux, Cumhur Erkut, Jodi Forlizzi, Nassrin Hajinejad, Michae Haller, Caroline C M Hummels, Katherine Isbister, Martin Jonsson, George Khut, Lian Loke, Danielle Lottridge, Patrizia Marti, Edward Melcer, Florian Floyd Müller, Marianne Graves Petersen, Thecla Schiphorst, Elena Márquez Segura, Anna Ståhl, Dag Svanaes, Jakob Tholander, and Helena Tobiasson. 2018. Embracing First-Person Perspectives in Soma-Based Design. Informatics 5, 1 (February 2018). DOI:https://doi.org/10.3390/ informatics 5010008

[32] Elvin Karana, Bahareh Barati, and Elisa Giaccardi. Living Artefacts: Conceptualizing Livingness as a Material Quality in Everyday Artefacts. International Journal of Dsign 14:3. Available at http://blog.ijdesign.org/index.php/IJDesign/article/ view/3957

[33] Ruth A. Lawrence and Robert Lawrence. 2005. Breastfeeding: A Guide for the Medical Profession (6th edition ed.). Mosby, St. Louis.

[34] Robyn Lee. 2018. Breastfeeding Bodies: Intimacies at Work. Gender, Work \& Organization 25, 1 (2018), 77-90. DOI:https://doi.org/10.1111/ gwao. 12170

[35] Robyn Lee. 2018. The Ethics and Politics of Breastfeeding: Power, Pleasure, Poetics. University of Toronto Press.

[36] Robyn Lee. 2019. Commodifying Compassion: Affective Economies of Human Milk Exchange. IJFAB: International Journal of Feminist Approaches to Bioethics 12, 2 (August 2019), 92-
116. DOI:https://doi.org/10.3138/ijfab.12.2.06

[37] Robyn Lee. 2019. Queering Lactation: Contributions of Queer Theory to Lactation Support for LGBTQIA2S+ Individuals and Families. J Hum Lact 35, 2 (May 2019), 233-238. DOI:https://doi.org/10.1177/0890334419830992

[38] Jen Liu, Daragh Byrne, and Laura Devendorf. 2018. Design for Collaborative Survival: An Inquiry into Human-Fungi Relationships. In Proceedings of the 2018 CHI Conference on Human Factors in Computing Systems (CHI '18). Association for Computing Machinery, New York, NY, USA, Paper 40, 1-13. DOI:https://doi. org/10.1145/3173574.3173614

[39] Adetola F. Louis-Jacques, Stephanie L. Marhefka, Jessica Brumley, Ellen J. Schafer, Tomaro I. Taylor, Alyssa J. Brown, Taylor A. Livingston, Diane L. Spatz, and Elizabeth M. Miller. 2020. Historical Antecedents of Breastfeeding for African American Women: from the Pre-Colonial Period to the MidTwentieth Century. J. Racial and Ethnic Health Disparities 7, 5 (October 2020), 1003-1012. DOI:https://doi.org/10.1007/s40615-020-00727-5

[40] Mekha McGuire. 2018. Black Breastfeeding after a History of Trauma. HealthConnect One. Retrieved February 19, 2021 from https://www. healthconnectone.org/black-breastfeeding-after-ahistory-of-trauma/

[41] Yoriko Otomo. 2014. The Gentle Cannibal: The Rise and Fall of Lawful Milk. Australian Feminist Law Journal 40, 2 (July 2014), 215-228. DOI:https://doi.org/10.1080/13200968.2014.10 08097

[42] Jeroen Peeters, Rosa van der Veen, and Ambra Trotto. 2020. Pictorial Unleashed: Into the Folds of Interactive Qualities. Proceedings of the 2020 ACM Designing Interactive Systems Conference. 
Association for Computing Machinery, New York, NY, USA, 925-938. DOI:https://doi. org/10.1145/3357236.3395570

[43] James Pierce. 2019. Smart Home Security Cameras and Shifting Lines of Creepiness: A DesignLed Inquiry. In Proceedings of the 2019 CHI Conference on Human Factors in Computing Systems (CHI '19), Association for Computing Machinery, New York, NY, USA, 1-14. DOI:https://doi.org/10.1145/3290605.3300275

[44] Jane Rendell. 2010. Site-writing: The Architecture of Art Criticism. I.B. Tauris \& Company Limited.

[45] Margrit Shildrick. 2015. Leaky Bodies and Boundaries : Feminism, Postmodernism and (Bio)ethics. Routledge. DOI:https://doi. org/10.4324/9781315004952

[46] Margrit Shildrick. 2019. (Micro)chimerism, Immunity and Temporality: Rethinking the Ecology of Life and Death. Australian Feminist Studies 34, 99 (January 2019), 10-24. DOI:https://doi.org/10.1080/08164649.2019.16 11527

[47] Marie Louise Juul Søndergaard, Ozgun Kilic Afsar, Marianela Ciolfi Felice, Nadia Campo Woytuk, and Madeline Balaam. 2020. Designing with Intimate Materials and Movements: Making "Menarche Bits". Proceedings of the 2020 ACM Designing Interactive Systems Conference. Association for Computing Machinery, New York, NY, USA, 587-600. DOI:https://doi. org/10.1145/3357236.3395592

[48] Sally Sutherland. Rethink Milk. Sally Sutherland. Retrieved August 17, 2020 from https://www. sallysutherland.org/rethinkmilk

[49] Judy Torgus. 1987. The Womanly Art of Breastfeeding. La Leche League International.
[50] Vasiliki Tsaknaki, Karey Helms, Marie Louise Juul Søndergaard, and Marianela Ciolfi Felice. 2021. "Vibrant Wearables": Material Encounters with the Body as a Soft System. Journal of Textile Design Research and Practice (forthcoming).

[51] Emily West and R. J. Knight. 2017. Mothers' Milk: Slavery, Wet-Nursing, and Black and White Women in the Antebellum South. Journal of Southern History 83, 1 (2017), 37-68. DOI:https://doi.org/10.1353/soh.2017.0001

[52] Paulina Yurman. 2017. Designing for Ambivalence: Mothers, Transitional Objects and Smartphones. In Proceedings of the 2017 CHI Conference Extended Abstracts on Human Factors in Computing Systems (CHI EA '17). Association for Computing Machinery, New York, NY, USA, 344-348. DOI:https://doi.org/10.1145/3027063.3027120 